\title{
CONDUCTAS COLUSORIAS: DEL DERECHO ROMANO A LA LEY 15/2007 DE DEFENSA DE LA COMPETENCIA
}

\author{
José Luis Zamora Manzano ${ }^{1}$ \\ Tewise Yurena Ortega Gonzalez ${ }^{2}$
}

\begin{abstract}
Resumen
En el presente estudio, nos planteamos como objetivos el estudio de la especulación de los mercados en la época romana tratando de abordar los comportamiento que afectan a la libre competencia y que son perseguidos por instrumentos normativos como la lex iulia annonaria del año 18 a efectos de mantener el orden en los mercados ya que trato de reprimir el acaparamiento de productos alimenticios a fin de provocar una subida de precios artificial, a fin de indagar en los principios que se mantienen vigentes en el Derecho moderno como en la ley de Defensa de la competencia Ley 15/2007 de 3 de julio. Para ello, nuestra metodología se basa en análisis exegético de las fuentes romanas propuestas. Los resultados a destacar que también se reflejan en las notas conclusivas permiten observar como existe un trasunto fiel en el ámbito de las conductas colusorias del Derecho romano al vigente.
\end{abstract}

Palabras clave: Colusión; Annona; Monopolio; Dardanarii; Especulación Mercantil.

\section{CONSIDERACIONES PREVIAS EN CLAVE ECONÓMICA: EL MERCADO ROMANO}

El artículo 38 de la Constitución Española reconoce la libertad de empresa en el marco de una economía de mercado y la garantía y protección de la misma por los poderes públicos, de acuerdo con las exigencias de la economía en general y, en su caso, de la planificación. La existencia de una competencia efectiva entre las empresas constituye uno de los elementos definitorios de la economía de mercado, disciplina la actuación de las empresas y reasigna los recursos productivos en favor de los operadores o las técnicas más eficientes. Esta eficiencia productiva se traslada al consumidor en la forma de menores precios o de un aumento de la cantidad ofrecida de los productos, de su variedad y calidad, con el consiguiente incremento del bienestar del conjunto de la sociedad. En este contexto, existe un acuerdo generalizado con respecto a la creciente importancia de la defensa de la competencia, que se ha consolidado como uno de los elementos principales de la política económica en la

\footnotetext{
${ }^{1}$ Profesor Titular de Derecho romano en la Universidad de las Palmas de Gran Canaria (España) y profesor tutor del Centro Asociado de las Palmas de la Universidad Nacional de Educación a Distancia de Madrid. E-mail: joseluis.zamora@ulpgc.es.

${ }^{2}$ Doctora y profesora colaboradora del área de Derecho romano de la Universidad de las Palmas de Gran Canaria (España). Email: tewortgo@gmail.com
} 
actualidad a fin de poder dar un marco jurídico que logre reforzar los mecanismos de control y dotar al sistema de los instrumentos y la estructura institucional óptima para proteger la competencia efectiva en los mercados, surge la Ley 15/2007 de 3 de Julio de Defensa de la competencia. En dicha ley, en su artículo 1, se establecen cuáles son las conductas colusorias prohibidas:

Se prohíbe todo acuerdo, decisión o recomendación colectiva, o práctica concertada o conscientemente paralela, que tenga por objeto, produzca o pueda producir el efecto de impedir, restringir o falsear la competencia en todo o parte del mercado nacional y, en particular, los que consistan en:

a) La fijación, de forma directa o indirecta, de precios o de otras condiciones comerciales o de servicio.

b) La limitación o el control de la producción, la distribución, el desarrollo técnico o las inversiones.

c) El reparto del mercado o de las fuentes de aprovisionamiento.

d) La aplicación, en las relaciones comerciales o de servicio, de condiciones desiguales para prestaciones equivalentes que coloquen a unos competidores en situación desventajosa frente a otros.

e) La subordinación de la celebración de contratos a la aceptación de prestaciones suplementarias que, por su naturaleza o con arreglo a los usos de comercio, no guarden relación con el objeto de tales contratos.

En el artículo se recogen los aspectos sustantivos sobre las conductas colusorias que atentan contra la libre competencia, cuyos precedentes encontramos en el Derecho romano, así, al igual que sucede en la actualidad, también existía en Roma un mercado competitivo donde los consumidores y los productores eran precio-aceptantes ya que en situaciones de libre concurrencia las condiciones del precio venían fijadas únicamente por la oferta y la demanda. Por ello, era importante saber quién tenía el poder de mercado, esto es, la capacidad de influir en el precio de un determinado bien. Sin embargo, encontramos situaciones, como tendremos ocasión de analizar en nuestro estudio, donde fue frecuente que los comerciantes y productores llevasen a cabo acuerdos y diversos mecanismos para ejercer el control en la cantidad de producción y del precio, aunque no fuera de forma simultánea, determinando la tasa de producción que maximizara las ganancias que podían obtener en la venta, provocando situaciones de monopolio en el mercado, afectando al orden del mercado en Roma.

A mayor abundamiento, uno de los problemas que se plantea en la sociedad actual ${ }^{3}$ es el acaparamiento y control de precios en el ámbito, sobre todo de los cereales, la irregularidad de la compraventa del trigo es donde se advierten, los radicales defectos de la actual ordenación económica. Pues es un producto que se presta, como ningún otro, a la más perfecta regulación de su mercado, donde normalmente la producción y el consumo casi se

\footnotetext{
${ }^{3}$ En el tratado de funcionamiento de la Unión Europea se hace mención específica a este tipo de comportamientos en el art. 101 (antes 81) cuando señala: serán incompatibles con el mercado interior y quedarán prohibidos todos los acuerdos entre empresas, las decisiones de asociaciones de empresas y las prácticas concertadas que puedan afectar al comercio entre los Estados miembros y que tengan por objeto o efecto impedir, restringir o falsear el juego de la competencia dentro del mercado interior y, en particular, los que consistan en, entre otras: fijar directa o indirectamente los precios de compra o de venta u otras condiciones de transacción; limitar o controlar la producción, el mercado, el desarrollo técnico o las inversiones; repartirse los mercados o las fuentes de abastecimiento...
} 
nivelan de un modo natural. En este sentido, tras el colapso inmobiliario, asistimos a un mercado alimentario especulativo desnaturalizado y con una enorme volatilidad en los precios que conlleva adversos efectos tanto para los cultivadores, a veces con excesos de producción innecesarios, como para los consumidores sobre los que sólo se repercuten de inmediato las subidas de los precios.

Es cierto, que siempre ha habido quien se ha aprovechado en la crisis del abastecimiento y subsistencia, principalmente, mediante acaparamiento de alimentos que forzaba su encarecimiento o bien buscando el lucro excesivo a costa de los productos de primera necesidad. En este sentido, uno de los principales problemas a los que se enfrentó la sociedad romana fue la del aprovisionamiento urbano ${ }^{4}$ de grano y trigo, la annona, que era ya desde la época Republicana una actividad encomendada a los ediles ${ }^{5}$ que debían de controlar la provisión del grano en cantidades suficientes y a un precio razonable. Pero los ediles encontraban dificultades a la hora de adoptar medidas frente a los especuladores, de ahí que muchas veces se produjera una intervención directa de la Administración romana buscando solución a la carestía y provisión de cereales ${ }^{6}$, intentando también controlar las fluctuaciones de precios. Ello requería una importante organización ${ }^{7}$ de la anonna $a^{8}$ que tuviese en cierta medida bajo control el alza de los precios que, muchas veces, era insoportable para la población. Sobre todo a partir de la segunda guerra púnica' ${ }^{9}$ donde se va agudizando por el encarecimiento artificial de los cereales y las coaliciones de especuladores que alteraban el precio de los productos acaparando los mismos, a fin de obtener cuantiosos beneficios, lo cual incide en los intentos de atajar el liberalismo marcando un nuevo orden económico ${ }^{10}$.

En resumidas cuentas, la situación de carestía del abastecimiento se produjo por la disminución de la producción ${ }^{11}$ de cereales en Italia, lo que implicó, lógicamente, un aumento de los precios. Ante esta necesidad, los ediles debían de buscar soluciones, y, por este motivo, se daba la intervención directa y el control de los mercados

\footnotetext{
${ }^{4}$ Es evidente que a ello contribuyó también el progreso técnico en la agricultura, donde se observan nuevos modelos organizativos y técnicos en este ámbito vid. KOLENDO, J., L 'agricoltura nell 'italia romana, Tecniche agrarie e progesso economico dalla tarda repubblica al principato ( Roma 1980) 179 ss y OLIVA A., La politica granaría di Roma antica dal 265 a.C. al 410 d.C. Saggio di agricultura ed economia rurale, Piacenza, 1930.

${ }^{5}$ Sobre las funciones vid. Cic. de leg. 3.3.7; de off.2.17.58; Plin. nat. Hist. 15.1.2; 18.3.15.16, Liv. 10.11.19; 32.42.8 cit. De Ruggiero, s.v.«aediles». citen relación a la anonna, 233 ss.

${ }^{6}$ ROSTOVZEV, M., Storia economica e sociale dell 'impero romano, Firenze, 1933p. 33 ss. alude a la complejidad de asegurar los víveres en la ciudad. Vid. MARQUARDT K.J, Del'organisation financière chez les romains, Paris ,1988, p. 140 ss.

${ }^{7}$ HÖBENREICH E., Annona, Juristiche aspekte der Stadrömischen Lebesmittelversordung im Prinzipat Graz, 1997,p. 24 ss.

${ }^{8}$ No vamos a estudiar las posibles acepciones pero si señalar las que se han ido barajado de forma común como suministro urbano, D.48.19.37, D.49.12.1, D.50.4.1.2, D. 50.5.10, D. 50.8.12; precio de los víveres D.47.11.6, D.48.12.2.3, D.50.8.7, también el de víveres, entre otros, Cic., in verr. 5.98, dom. 5.6, Tac. Ann. 1.7, Colum.3.21.6. sin olvidarnos de su valor como vectigal canonis annonarii. Vid. Thesaurus Linguae Latina, v. annona, II (Lipsiae 1900) col. 110-113.

${ }^{9}$ MAIER E.G, "Römische Bevolkerungsgeschichte Uninschriftenstatt", Historia 2, 1953, p. 318 ss.

${ }^{10}$ LO CASCIO E., Crescita e decline, Studi di storia dell 'economia romana, Roma, 2009 p. 274 ss nos comenta como l'autorita imperiale può svolgere anche una funzione di regolamentazione del mercato.

${ }^{11}$ RICKMAN G.E., The corn supply of Ancient rome, Oxford, 1980 p. 143 ss; DE MARTINO F., Produzione di cereal in Roma nell 'età antica, 1979 p. 241 ss.
} 
por parte de la Administración para garantizar el regular aprovisionamiento ${ }^{12}$, ordenando la venta de grano a precio más reducido y por tanto más razonable ${ }^{13}$. De hecho, muchas veces el cereal era importado de fuera mediante el expolio que Roma hacía depauperando las provincias ${ }^{14}$, agudizando más las diferencias de unas y otras. Los propios ediles no podían controlar las irregularidades que se cometían con la manipulación comercial que sufría el grano y la situación de libre mercado sin intervencionismo que operaba durante la República; ello provocó un alza de precios y la especulación de un producto de primera necesidad como eran los cereales, que afectaba a toda la población, menos a los ejércitos que contaban siempre con el suministro necesario ${ }^{15}$.

Todo este contexto provocó numerosas irregularidades que influyeron negativamente en el orden público de la economía y de la sociedad, se fueron gestando en un iter histórico ${ }^{16}$ que afectó al orden público económico, en el cual se puede destacar en primer lugar desde el año $492{ }^{17}$ ante la notable escasez se produce la intervención para tratar de paliar la grave hambruna por parte de Espurio Casio ${ }^{18}$ a fin de poder asegurar la llegada de grano; pero los problemas crecen ${ }^{19}$ y de nuevo en el año 474 a.C. los cónsules envían a delegados a los territorios vecinos para comprar grano, obligando el Estado a vender trigo a aquellos que lo han almacenado a fin

\footnotetext{
${ }^{12}$ Sobre el funcionamiento de la annona y el transporte de trigo vid. SIRKS B., Food for rome. The legal structure of the transportation and processing of supplies for the imperial distributions in rome and Constantinopla, Amsterdam, 1991, p. 12 ss.

${ }^{13}$ DE RUGGIERO s.v. «annona»... cit. p.362 ss., en cuanto a las fuentes literarias que aluden a la situación problemática vid. Liv. 10.1 1.9, 30.26.6, 33.42.8, 50.1, Plin. Hist.nat. 18.3.15, Dion. Hal6.90 y Cic. De Leg. 3.3.7 y In verr.5.14

${ }^{14}$ Dos fragmentos de Tácito ilustran la dependencia de roma del cereal que se importaba de Italia, Africa Egipto, España, Sicilia y Cerdeña Tac. Ann. 3.54: ... quantulum istud est de quo aediles admonent! quam, si cetera respicias, in levi habendum! at hercule nemo refert quod Italia externae opis indiget, quod vita populi Romani per incerta maris et tempestatum cotidie volvitur. ac nisi provinciarum copiae et dominis et servitiis et agris subvenerint, nostra nos scilicet nemora nostraeque villae tuebuntur. hanc, patres conscripti, curam sustinet princeps; haec omissa funditus rem publicam trahet. reliquis intra animum medendum est: nos pudor, pauperes necessitas, divites satias in melius mutet. aut si quis ex magistratibus tantam industriam ac severitatem pollicetur ut ire obviam queat, hunc ego et laudo et exonerari laborum meorum partem fateor: sin accusare vitia volunt, dein, cum gloriam eius rei adepti sunt, simultates faciunt ac mihi relinquunt, credite, patres conscripti, me quoque non esse offensionum avidum; quas cum gravis et plerumque iniquas pro re publica suscipiam, inanis et inritas neque mihi aut vobis usui futuras iure deprecor, en igual sentido Ann.12.43: alimenta urbi, non amplius superfuisse constitit, magnaque deum benignitate et modestia hiemis rebus extremis subventum. at hercule olim Italia legionibus longinquas in provincias commeatus portabat, nec nunc infecunditate laboratur, sed Africam potius et Aegyptum exercemus, navisbusque et casibus vita populi Romani permissa est...

${ }^{15}$ Vid. Tito Liv. 36.12.2

${ }^{16}$ Seguimos la amplia exposición del iter histórico de POLLERA A. "Annonam adtemplare et vexare vel maxime dardanarii solent, D.47.11.6: note sulla repressione dei crimini annonari”, Index 19, 1991, p. 406 ss n.10, seguido de la misma forma sin variaciones por TORRENT A., "Crimen annonae y mantenimiento del orden público económico", en El derecho comercial, de Roma al Derecho moderno Las Palmas de Gran Canaria, 2007, p. 1008 ss.

${ }^{17}$ GARNSEY P., Famine and food supply in the graeco-roman world,Cambridge, 1988 p. 169 ss., el a. sostiene como la principal causa no solo el alza de precios, sino la escasez de grano: .. is recorded tha a rise in the price of grain was followed by a severe food crisis such as hits a city under siege... En igual sentido vid. del mismo autor Food society in classical antiquity,Cambridge, 1999, p. 34 ss.

${ }^{18}$ Liv. 2.41.7-12: Cassius, quia in agraria largitione ambitiosus in socios eoque ciuibus uilior erat, ut alio munere sibi reconciliaret ciuium animos, iubere pro Siculo frumento pecuniam acceptam retribui populo. Id uero haud secus quam. Dion Hal.8.70.5: kai iñs

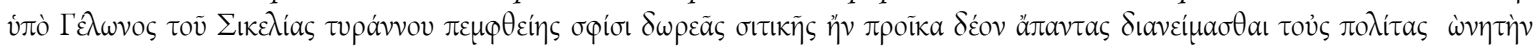

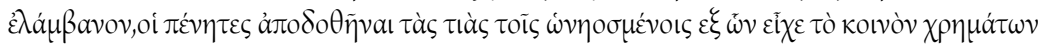


de que esto sea a precio razonable, ello con el antecedente del año 439 a.C. en el que se había producido el alza de precios y la falta de abastecimiento alimenticio, a lo que se le unió la tensión social entre patricios y plebeyos, de hecho estas circunstancias y la especulación provocaron la muerte de muchos plebeyos ${ }^{20}$. Además, se aprobó el plebiscito de cura annonae de Lucio Minicio, que había sido miembro del segundo colegio decenviral en el 450 a.C. y a ello se le suma el trágico suceso de Spurio Melio que muere ejecutado al ser acusado de aspiración a la tiranía, es decir de adfectatio regni, por pretender vender trigo de Etruria a dos denarios el modio. La situación no parece ser fácil según nos informa Liv. 4.12.8-9: Postremo perpulere plebem, haud adversante senatu, ut L. Minucius praefectus annonae crearetur, felicior in eo magistratu ad custodiam libertatis futurus quam ad curationem ministerii sui, quamquam postremo annonae quoque leuatae haud immeritam et gratiam et gloriam tulit. Qui cum multis circa finitimos populos legationibus terra marique nequiquam missis, nisi quod ex Etruria haud ita multum frumenti advectum est, nullum momentum annonae fecisset.

Sin embargo, no quedó resuelta del todo la situación de hambruna ya que se producen nuevas intervenciones con posterioridad, basadas en importación de trigo como respuesta a la carestía ${ }^{21}$. Así destaca la Fabio Máximo (299 a.C) $)^{22}$ y la de los ediles curules Falto y Buteón como nos informa Liv.30.26.6: sed annonae uilitate fuit, praeterquam quod pace omnis Italia erat aperta, etiam quod magnam uim frumenti ex Hispania missam M. Ualerius Falto et M. Fabius Buteo aediles curules quaternis aeris uicatim populo discripserunt; que también traen trigo de zona extraitálico en esta ocasión de Hispania. Va a ser en ese período y, gracias a los ediles curules, en los que se trae cierta estabilidad de los mercados entre el 201 y 200 a.C. ${ }^{23}$ al estabilizarse el precio a unos dos ases el modio de trigo que se mantienen en el 186 por los ediles Flaminioy Nobilitor.

De los textos citados, se infiere que fueron varias las medidas que trataron de atajar el problema, unas veces con iniciativa privada a la importación de cereales, otras mediante el envío de embajadores a países vecinos a fin de obtener un trigo a precio reducido, fijando los precios de adquisición de los mismos que se obtenía como botín de guerra o incluso racionalizando la cantidad que podía adquirir un ciudadano; llegándose incluso a

\footnotetext{
${ }^{19}$ Liv. 2.52: Urbi cum pace laxior etiam annona rediit, et aduecto ex Campania frumento, et postquam timor sibi cuique futurae inopiae abiit, eo quod abditum fuerat prolato. Ex copia deinde otioque lasciuire rursus animi et pristina mala, postquam foris deerant, domi quaerere.

${ }^{20}$ Liv. 4.12-9 : nullum momentum annonae fecisset, et revolutus ad dispensationem inopiae, profiteri cogendo frumentum et vendere quod usui menstruo superesset, fraudandoque parte diurni cibi seruitia, criminando inde et obiciendo irae populi frumentarios, acerba inquisitione aperiret magis quam leuaret inopiam, multi ex plebe, spe amissa, potius quam ut cruciarentur trahendo animam, capitibus obuolutis se in Tiberim praecipitauerunt.

${ }^{21}$ GARNSEY P., Famine and food ... cit. 178 ss

${ }^{22}$ Liv. 10.11.9: Caritas etiam annonae sollicitam ciuitatem habuit uentumque ad inopiae ultimum foret, ut scripsere quibus aedilem fuisse eo anno Fabium Maximum placet, ni eius uiri cura, qualis in bellicis rebus multis tempestatibus fuerat, talis domi tum in annonae dispensatione praeparando ac conuehendo frumento fuisset. Eo anno — nec traditur causa — interregnum initum 23 ... aedilibus curulibus L. Valerio Flacco et L. Quinctio Flaminino; biduum instauratum est; frumentique uim ingentem quod ex Africa P. Scipio miserat quaternis aeris populo cum summa fide et gratia diuiserunt, Liv.31.4.6. ID. frumenti uim magnam ex Africa
} 
solicitar al Senado la provisión de fondos públicos para la adquisición del grano a precio razonable, todo ello antes de que se fuera acentuando la crisis que llamaba a la creación de políticas directas de estabilización de los mercados que evitaran la subida de precios y garantizase un aprovisionamiento en niveles óptimos ${ }^{24}$.

Es cierto que existieron enormes dificultades ${ }^{25} y$, desde época republicana, existe ya intervencionismo por parte de la Administración para impedir la formación de coaliciones de especuladores que podían crear lo que hoy conocemos por trusts. Sin embargo, no existían unas líneas políticas de actuación que permitieran una represión penal específica, tan sólo se imponían multas ante este tipo de actuaciones que implican un acaparamiento o un concilium inire en el ámbito mercantil, como veremos más adelante ${ }^{26}$. La resolución de conflictos se producía de manera irregular y coyuntura ${ }^{27}$ con medidas que se inician desde las acciones políticas de los hermanos Graco, con la aplicación de leges frumentariae, y el uso de otros instrumentos que van a tratar de frenar el liberalismo del mercado, que operaba por iniciativa de los mercatores, con un intervencionismo en materia de control de precios y abastecimiento en los mercados; si bien, muchas tuvieron un fin político, ya que existieron medidas demagógicas

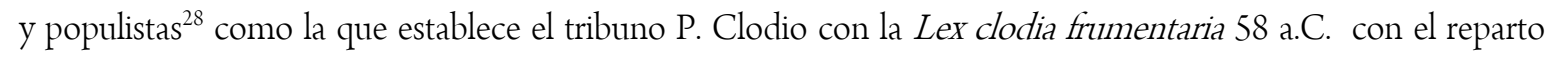
gratuito de trigo ${ }^{29}$.

Asimismo, en el año 67 a.C., como señala Tramonti ${ }^{30}$, se agudiza el problema de la piratería en el mediterráneo y se organiza operaciones militares para combatirla ya que afectaba a la seguridad y transporte de mercancías, en nuestro caso el grano, de ahí que el Senado confiriera a Pompeyo poderes extraordinarios durante un lustro para tratar de restaurar el normal abastecimiento del cereal según nos informa Cicerón Ad. Att.,4.1.7: postridie senatus frequens et omnes consulares nihil Pompeio postulanti negarunt. ille legatos quindecim cum

aduectam aediles curules M. Claudius Marcellus et Sex. Aelius Paetus binis aeris in modios populo diuiserunt. et ludos Romanos magno apparatu fecerunt; diem unum instaurarunt; signa aenea quinque ex multaticio argento in aerario posuerunt, Liv.31.50.1.

${ }^{24}$ VEYNE P., Le pain et le cirque sociologie historique d'un pluralisme politique, Paris, 1976, p. 454 ss.

${ }^{25}$ VIRLOUVET V., Famines et émeutes à Rome des origines de la republique a la mort de Neron, Roma, 1985 p. 15 ss.

${ }^{26}$ Liv. 38.35.5: Et duodecim clipea aurata ab aedilibus curulibus P. Claudio Pulchro et Ser. Sulpicio Galba sunt posita ex pecunia, qua frumentarios ob annonam compressam damnarunt. En igual sentido Plauto, Capit, 494-5... nunc barbarica lege certumst ius meum omne persequi: qui consilium iniere, quo nos victu et vita prohibeant, is diem dicam, irrogabo multam, ut mihi cenas decem meo arbitratu dent, cum cara annona sit. sic egero. Vid. GAROFALO F., Aediles e iudicia populi, Idee vecchie e nuove sul diritto criminale romano,Padova, 1988, p. 69 ss n.98.

${ }^{27}$ DE MARTINO F., Storia economica di Roma antica II, Firenze, 1979, p. 337 ss. señala en relación a la economía: que non si puó dire che vi fosse una vera e propia politica commerciale del governo né che esso venisse influenzato nelle sue decisioni da interessi dicarattere commerciale.

${ }^{28}$ Otra ley la Lex Terentia Cassia hace mención de las dificultades de abastecimiento de grano y restaura la distribución, si bien limita la ración a 5 modios por persona y mes. En los textos de las verrinas de Cic. Verr.2.163; 5.52 nos comenta como Verres como gobernador de Sicilia compra tres millones de modios a tres sestercios por modio y una cantidad adicional de ochocientos mil modios a tres sestercios y medio, asi lo hizo durante tres años en el cargo.

${ }^{29}$ VEYNE P., Le pain et le cirque ... cit. 455 ss.

${ }^{30}$ Hostes comunes ommnium. La piratería e la fine della repubblica romana( 145-33 aC), Ferrara, 199461 considera que: 1'anno 67 a.C, rappresenta indubbiamente una data extremamente importante, se non altro per il fatto che la stessa piratería da fenómeno particolare o da fattore concomitante insieme ad altri per la determinazione di singoli eventi assurge alla funzione di elemento 
postularet, me principem nominavit et ad omnia me alterum se fore dixit. legem consules conscripserunt qua Pompeio per quinquennium omnis potestas rei frumentariae toto orbe terrarum daretur, alteram Messius qui omnis pecuniae dat potestatem et adiungit classem et exercitum et maius imperium in provinciis quam sit eorum qui eas obtineant ${ }^{31}$.

Entre el 58 y 56 a.C. se produce una salvaje fluctuación de precios debido a la carestía de grano ${ }^{32}$ : sobre todo desde que Cicerón parte al exilio en abril del año 58, posteriormente a su llegada en septiembre del 57 propone a Pompeyo que controle el suministro de grano, otorgándole el Senado cuarenta millones de sestercios a éste último por la comisión del grano. A pesar de las medidas, hubo una inundación en el año 54 que acabo con el suministro lo que obligo a Pompeyo a buscar provisiones de emergencia ${ }^{33}$. La guerra entre Cesar y Pompeyo colocó a la población en un gran riesgo, bloqueándose el suministro de alimentos y en particular el de trigo.

El intervencionismo de la Administración de Cesar en el año 49 a C trató de atajar el problema, creando unos ediles ceriales ${ }^{34}$ a fin de controlar los mercados y los desmanes de la especulación. Sin embargo, a pesar de haber reforzado esta magistratura, no se logra contrarrestar los problemas sociales y la escasez, esto hace que en el año 22 Augusto tome las riendas de la cura annonae; así en Res gestae divi Augusti 5.2 señala que: Non recusavi in summa frumenti penuria curationem annonae, quam ita administravi, ut intra paucos dies metu et periclo praesenti populum universum liberarem impensa et cura mea. Consulatum quoque tum annuum et perpetuum mihi delatum non recepi; dónde el Emperador nos comenta que no se opuso, en momentos de tremenda escasez de trigo, a la administración y racionamiento de los víveres para tratar de evitar los peligros del desabastecimiento ${ }^{35}$.

Ante este contexto de mercado se crea la figura del Prefecto anonnae ${ }^{36}$, encargado de la política de racionamiento y control de los cereales y alimentos a través del marco jurídico que instituye la lex iulia annonaria del año 18 a efectos de mantener el orden en los mercados ya que trato de reprimir el acaparamiento de productos alimenticios a fin de provocar una subida de precios artificial y, en particular, de los cereales, ya fuera mediante la

d'interesse centrale e sul quale viene a focalizzarsi I' attenzione della produzione storiografica antica vid. Liv. Per:99, App., Mithr.9496, Plut. Pomp. 24-37 y Cic. de imp. Cn. Pomp. 31-35.

${ }^{31}$ BALDSON J. P., "Roman history 58-56 BC. Three Ciceronian problems," JRS, 45,1957, p. 13-18 ss, dónde el autor considera que por un lado la medida trato de restaurar el regular abastecimiento de grano y por otro la frumentatio si bien en este punto era necesario una lista oficial de los ciudadanos de la ciudad : regularize the frumentatio, the distribution of the corn ration in Rome... there was need fo an oficcial list of bona fide residentes in the city.

${ }^{32}$ Según nos informan los fragmentos de Dio Cass. 39,9.3, Plut. Pomp.49.4; 50.2.

${ }^{33}$ Vid. Dio Cass. 39.63.3.

${ }^{34}$... caesar duos praetores et duos aediles qui frumento praeessent et a cerere cereales constituit, ... vid. D.1.2.2.32. Vid. también Suet, Caes.41.

${ }^{35}$ Vid. Dio Cass. 54.1.1 y Vell. Pat. 2.89.

${ }^{36}$ Asume las funciones de los ediles ceriales con la ventaja de no tener límite temporal en el desempeño de su labor, con funciones más allá de las mera supervisión y custodia de los horrea para convertirse en intermediarios y negociadores con los mercatores y sociedades de naviero tratando de garantizar las provisiones y evitar la especulación. 
creación de monopolios o agrupaciones de proveedores, auténticos trusts, con el fin de acaparar y provocar la alteración de los precios. Por ello, la política económica trato de incentivar a aquellos que desempeñaban un servicio a favor de la annona, consiguiendo a cambio ventajas y exenciones fiscale ${ }^{37}$; de una política liberal de mercado pasamos a una política annonaria intervencionista. De hecho es significativo, bajo mi punto de vista, cómo durante los meses de invierno, en los que la navegación era bastante complicada sobre todo entre noviembre y abril, existe la necesidad de incentivar el transporte para evitar la falta de provisiones, así Claudio induce a los negotiatores a que acometan dicho transporte reembolsando a los mismos gastos por los daños o pérdidas que puedan acaecerles durante la navegación a fin de incentivar los viajes, como nos informa Suetonio en Clad. 18.4:

nihil non excogitavit ad invehendos etiam tempore hiberno commeatus. Nam et negotiatoribus certa lucra proposuit suscepto in se damno, si cui quid per tempestates accidisset, et naves mercaturae causa fabricantibus magna commoda constituit pro condicione cuiusque

Esta medida, sin lugar a dudas, constituía un acicate para los comerciantes que no querían exponer sus naves sin una garantía, en este sentido también el emperador Trajano garantizo esta política de incentivos, mediante vacatio muneris publicia los naviculariique servían a la annona $a^{38}$.

\section{COLUSIÓN Y MERCADO DE CEREALES}

La especulación, ejerce una función económica de equilibrar temporalmente la oferta y la demandad, si bien el fin privado que persigue es, como en toda actividad comercial, la consecución del beneficio de unos pocos, por ello estas acciones van dirigidas a aprovecharse y lucrarse, ejerciendo produciendo un encarecimiento artificial de los precios. Precisamente, en términos actuales, la especulación nació en el negocio al contado y no a plazo, es decir, los especuladores compraban grandes partidas de cereal y las almacenaban hasta que la demanda hacía subir los precios. Así, nos encontramos con este tipo de maquinaciones desde época Republicana que tratan de solventarse por parte de la Administración dado que afectan a la libre competencia y al mercado y consumo de

\footnotetext{
${ }^{37}$ Encontramos referencias específicas a los privilegios en textos que pertenecen a una época ulterior como nos el texto D.50.6.6.3 (Calistrato $1 \mathrm{De}$ Cog.) Negotiatores, qui annonam urbis adiuvant, item navicularii, qui annonae urbis serviunt, immunitatem a muneribus publicis consequuntur, quamdiu in eiusmodi actu sunt. nam remuneranda pericula eorum, quin etiam exhortanda praemiis merito placuit, ut qui peregre muneribus et quidem publicis cum periculo et labore fungantur, a domesticis vexationibus et sumptibus liberentur: cum non sit alienum dicere etiam hos rei publicae causa, dum annonae urbis serviunt, abesse y en S.5: Divus hadrianus rescripsit immunitatem navium maritimarum dumtaxat habere, qui annonae urbis serviunt.

${ }^{38}$ D.50.6.6.3 (Calistrato 1 De Cog.): Negotiatores, qui annonam urbis adiuvant, item navicularii, qui annonae urbis serviunt, immunitatem a muneribus publicis consequuntur, quamdiu in eiusmodi actu sunt. nam remuneranda pericula eorum, quin etiam exhortanda praemiis merito placuit, ut qui peregre muneribus et quidem publicis cum periculo et labore fungantur, a domesticis vexationibus et sumptibus liberentur: cum non sit alienum dicere etiam hos rei publicae causa, dum annonae urbis serviunt, abesse, en igual sentido vid. Bas.54.6.6.3. También es lapidario el rescripto de Adriano al que alude Calistrato en D.50.6.6.5: Divus hadrianus rescripsit immunitatem navium maritimarum dumtaxat habere, qui annonae urbis serviunt.
} 
alimentos básicos. Así nos informa Liv. 38.35.5: Et duodecim clipea aurata ab aedilibus curulibus P. Claudio Pulchro et Ser. Sulpicio Galba sunt posita ex pecunia, qua frumentarios ob annonam compressam damnarunt; et aedilis plebi Q. Fuluius Flaccus duo signa aurata uno reo damnato

Según se infiere del fragmento, ya en el año 189 a.C. los ediles curules ${ }^{39}$ imponían multas a los frumentarii, o especuladores, qué después veremos reciben el nombre de dardanarii, en un proceso apud populum en el que intervienen con el poder coercitivo los ediles ediles Claudio Pulcher y Servio Sulpicio Galba, esa misma coercitio edilicia se aprecia en el siguiente fragmento en relación al edil Quinto Fulvio Flaco que también impone a un acaparador de grano Liv. 38.35.5: et aedilis plebi Q. Fuluius Flaccus duo signa aurata uno reo damnato — nam separatim accusauerant - posuit ${ }^{40}$.Esa coercitio iría dirigida a evitar el desorden social que generaba la falta de provisiones, al margen de los intereses de los propios especuladores, podía existir unos intereses políticos en orden a crear un estado de malestar y agitación social ${ }^{41}$.

Asimismo, con anterioridad a la aparición de la lex Iulia de annona existía cierto control frente a la confabulación mercantil; así, en los captivi de Plauto, el comediógrafo latino nos referencia una ley, veamos el fragmento, Plaut., Capt.3.1.122:v.492-495:

nunc barbarica lege certumst ius meum omne persequi/;qui consilium iniere, quo nos victu et vita prohibeant/,is diem dicam, irrogabo multam, ut mihi cenas decem/, meo arbitratu dent, cum cara annona sit.

De la exégesis del inicio del fragmento, se observa que existía una ley que perseguía estas conductas y para ello utiliza la expresión barbarica lege cuya acepción debe interpretarse ${ }^{42}$, como romano o itálico. Por otro lado, el texto habla como conducta consilium iniere= concitarse a fin de especular; pero no parece a priori una medida efectiva a diferencia de lo que va a suceder con la disposición de la lex Iulia de annona que veremos a continuación; los versos hablan de una pena de multa ridícula haciendo alusión a diez cenas en tiempo de alza de precios irrogabo multam, ut mihi cenas decem. La brevedad del pasaje se centra en el comportamiento mercantil

\footnotetext{
${ }^{39}$ La ley de las XII tablas atribuyendo el conocimiento de las causas con condena capital al comicio centuriado no había privado ni a los tribunos ni a los ediles del conocimiento de de delitos que daban lugar a sanción pecuniaria y de instaurar procesos comiciales. BAUMAN R.A., "Criminal prosecutions by the aediles", Latomus 33 (1974) 257, n.78, dónde el autor trae a colación la preocupación desde la propia ley de las XII tablas de los supuestos de "qui fruges exantassit=( Plin. Nat hist. 28.2.17).. y el encatamiento sobre las mieses : neve alienam segetem pellexeris ( Tab 8.8.)

${ }^{40}$ Liv. 4.12.10:multum frumenti advectum est, nullum momentum annonae fecisset, et revolutus ad dispensationem inopiae, profiteri cogendo frumentum et vendere quod usui menstruo superesset, fraudandoque parte diurni cibi seruitia, criminando inde et obiciendo irae populi frumentarios ... vid. también 33.25.3; 33.42.10 y 38.35.6.

${ }^{41}$ Cic. de Dom. 11: Frumentum provinciae frumentariae partim non habebant, partim in alias terras, credo, propter avaritiam venditorum miserant, partim, quo gratius esset tum cum in ipsa fame subvenissent, custodiis suis clausum continebant, ut subito novum mitterent. Res erat non in opinione dubia, sed in praesenti atque ante oculos proposito periculo, neque id coniectura prospiciebamus, sed iam experti videbamus. Nam cum ingravesceret annona, ut iam plane inopia ac fames non caritas timeretur, concursus est ad templum Concordiae factus, senatum illuc vocante Metello consule. Qui si verus fuit ex dolore hominum et fame, certe consules causam suscipere, certe senatus aliquid consili capere potuit; sin causa fuit annona, seditionis quidem instimulator et concitator tu fuisti, nonne id agendum nobis omnibus fuit ut materiem subtraheremus furori tuo?

${ }^{42}$ FRAENKEL E,. Elementi plautini in Plauto, Firenze 1960, p. 237 ss.
} 
de encarecer el precio de los productos de primera necesidad y la pena pecuniaria, que tendrían que aplicar los ediles que se verían desbordados ante tales prácticas monopolísticas

Asimismo, la referencia de la comedia plautina a una ley, sin mencionar cual, puede entrar en el ámbito de la ley de las doce tablas que ya se tipificaban comportamientos en los que asociaciones podían coaligarse con pactos ilícitos Tab.8.27(= D.47.22.4): His sodalibus potestatem facit lex (XII tabularum), pactionem quam velint sibi ferre, dum ne quid ex publica lege corrumpant... Esa misma expresión aparece dentro de las conductas del crimen de maiestatis en el fragmento del D.48.4.1.1 ${ }^{43}$ (Ulp. 7 off. Pro.) consilium initum, concitarse mediante maniobras torticeras ${ }^{44}$. La identificación de la ley que nos comenta el texto de Plauto, con algunas conductas recogidas en otras leyes no está clara, son muchas las incertidumbres ${ }^{45}$ y en este sentido parece asemejarse más al crimen sodaliciorum o a la coitio, que podría constituir el antecedente a la formación de acuerdos no solo de carácter político sino económico con el fin de influir en el precio de las mercancías, si bien se sabía que llevaba aparejada una pena de multa ${ }^{46}$.

A mayor abundamiento, el texto referencia un conocimiento de estos comportamientos ilícitos, censurables y dignos de represión, en tanto en cuanto, a simple vista no sólo pueden verse intereses económicos de los propios especuladores, sino también, como ya hemos señalado, de forma indirecta podría pensarse que dichas actuaciones pueden ser generadas para que la carestía de cereales y de otros alimentos de primera necesidad, provoquen la agitación popular y afecte directamente a los órganos de gobierno.

Ahora bien, el detonante para configurar y tipificar las prácticas monopolísticas arranca en el año 22 a.C. ${ }^{47}$ por la situación de crisis y precariedad; ello hace que el emperador Augusto ${ }^{48}$ promulgue la lex iulia de annona ${ }^{49}$ en el año 18 a.C., que pone las bases precisas del delito que afecta a la libre concurrencia del mercado por

\footnotetext{
${ }^{43}$ Maiestatis autem crimen illud est, quod adversus populum romanum vel adversus securitatem eius committitur. quo tenetur is, cuius opera dolo malo consilium initum erit, quo obsides iniussu principis interciderent: quo armati homines cum telis lapidibusve in urbe sint conveniantve adversus rem publicam, locave occupentur vel templa, quove coetus conventusve fiat hominesve ad seditionem convocentur: cuilusve opera consilio malo consilium initum erit, quo quis magistratus populi romani quive imperium potestatemve habet occidatur: quove quis contra rem publicam arma ferat: quive hostibus populi romani nuntium litterasve miserit signumve dederit feceritve dolo malo, quo hostes populi romani consilio iuventur adversus rem publicam: quive milites sollicitaverit concitaveritve, quo seditio tumultusve adversus rem publicam fiat. Existen otras referencias de la expresión consilum inire en Liv. 2.8.2 y 4.15.4 pero en el contexto de la inducción a la affectatio regni.

${ }^{44}$ TORRENT A., Crimen annonae cit. 1014 ss, donde el a. habla de otras conductas pero que no encajan en el significado técnico de los juristas tardo-clásicos que en las comedias plautinas.

${ }^{45}$ RESINA SOLA, P. Prácticas monopolísticas cit.780, n.25.

${ }^{46}$ POLLERA A., Annonam adtemplare cit. 410 ss., considera que la multa edilicia para estos supuestos coincidía con la que disciplinaba la usura.

${ }^{47}$ Dion Cass. 54.1.4 y 54.17 .1

${ }^{48}$ La autoría de la ley es discutida por Mommsen que la atribuye al cesar "Alsdam ist das julische wharsheinlich von dem Dictator Caesar herrünhrende Gesetz gegen den Kornwucher ergangen und für die entsprechenden Criminalprozesse..” MOMMSEN T., Römisches Strafrecht, Leipzig, 1899 p. 851 ss.

${ }^{49}$ ROTONDI G., Leges publicae populi romani, Milano, 1912, p.448.
} 
parte de la coalición de especuladores llamados en época del Principado dardanarii ${ }^{50}$, que eran los que provocaban la escasez de cereales afectando a la oferta y por ende incidiendo en el alza de los precios.

Veamos cómo se configuran y tipifican las conductas ${ }^{51}$ que afectan a estos sujetos, en la rúbrica de lege iulia de annona del Digesto 48.12, la compilación recoge tres fragmentos uno de Marciano, otro de Ulpiano y finalmente uno de Papirio: así se establece en base a D.48.12.2pr (Ulp. 9 off. Proc.):

Lege iulia de annona poena statuitur adversus eum, qui contra annonam fecerit societatemve coierit, quo annona carior fiat.1.Eadem lege continetur, ne quis navem nautamve retineat aut dolo malo faciat, quo magis detineatur:2.Et poena viginti aureorum statuitur

Si analizamos los supuestos de hecho contemplados en la ley, que guardan semejanza con nuestra ley 15/2007 antes citada y, concretamente, con su art.1, podemos establecer como conductas colusorias:

1. Contra annonam fecerit, cualquier conducta que afecte a la distribución, este primer inciso de la ley parece determinado de forma genérica, es decir, conductas que afectan directamente al abastecimiento o amenacen al mercado

2. Constitución de sociedades de mercatores que tratan de especular y afectar a la libre competencia, tratando de crear trust o monopolios, societatemve coierit. En este sentido, se trata de confabularse a través de sociedades a fin de encarecer los precios annona carior fiat, es decir cualquier tipo de acción; así cuanto mayores eran los medios de que disponían los acaparadores, tanto más sensible era su influencia en la formación de precios, hasta el punto de afectar a las materias de primera necesidad. Es clara que la finalidad de la sociedad era obtener un lucro a consta de crear una crisis alimentaria y escasez, convirtiéndose en usureras del cereal.

3. Actos que implican la retenciçon de nave o que ésta no salga del puerto en el tiempo establecido quis navem nautamve retineat aut dolo malo faciat, quo magis detineatur; en este sentido, es importante destacar que existía un privilegio fiscal, vacatio munera, para aquellos que desempeñaban transporte al servicio de la annona ${ }^{52}$. Pero otra de las conductas que podemos incluir es el cambio de rumbo con dolo

\footnotetext{
${ }^{50}$ DU CANGE , s.v. «dardanarius», Glosarium mediat et infimae Latinitatis , t. III (Graz 1954) 9 cociator-arillator, l.grac. Паvor $\dot{\lambda} \lambda \eta$ s. Theasaurus Lingua Latina, s.v. «Dardanarius», vol V, Lipsiae 1910, col.38[ danus-ioculariter derivatum esse putent]. WALDE-HOFMAN, s.v. «dardanarius», t.I, Heidelberg, 1938,p 324 lo identifica con fenerator-danista-danisticus. Theasaurus Lingua Latina, s.v. «dardanarius», vol V, Lipsiae 1910, col.38[ danus-ioculariter derivatum esse putent].

${ }^{51}$ FERRINI C., Diritto penale romano, Roma, 1976, p. 411 ss.

52 D.50.6.5.3-5 (Cal. 1 de Cog.):: Negotiatores, qui annonam urbis adiuvant, item navicularii, qui annonae urbis serviunt, immunitatem a muneribus publicis consequuntur, quamdiu in eiusmodi actu sunt. nam remuneranda pericula eorum, quin etiam exhortanda praemiis merito placuit, ut qui peregre muneribus et quidem publicis cum periculo et labore fungantur, a domesticis vexationibus et sumptibus liberentur: cum non sit alienum dicere etiam hos rei publicae causa, dum annonae urbis serviunt, abesse.4. Immunitati, quae naviculariis praestatur, certa forma data est: quam immunitatem ipsi dumtaxat habent, non etiam liberis aut libertis eorum praestatur: idque principalibus constitutionibus declaratur. 5. Divus hadrianus rescripsit immunitatem navium maritimarum dumtaxat habere, qui annonae urbis serviunt.
} 
malo, para evitar que la mercancía llegue al puerto del porte, y evidentemente, que no quede justificado dicho motivo por incidente marítimo.

Se fija al final de párrafo la pena de 20 aureos equivalente a unos 200.000 sestercios que no va referida al supuesto de retención de naves, sino que lo entendemos aplicable a cualquiera de las conductas colusorias.

Nos centramos en las conductas que afectan a la libre competencia, no vamos aquí a analizar el procedimiento que crea la quaestio específica a juzgar el crimen de annonae, instituyendo la figura del praefectus annonae con facultades de supervisión del mercado y de disposición de stock de alimentos en los horrea que le permitiera intervenir sobre el precio de mercado, manteniendo un precio político de los alimentos básicos, controlando los precios y estabilizar el comercio de la annona.

El problema annonario afectaba a Roma y al resto del imperio, de hecho Ulpiano alude a los acaparadores o dardanarii, tratando de recoger estas conductas en su de officio proconsulis, D.47.1 1.6.pr:

Annonam adtemptare et vexare vel maxime dardanarii solent: quorum avaritiae obviam itum est tam mandatis quam constitutionibus. mandatis denique ita cavetur: "praeterea debebis custodire, ne dardanarii ullius mercis sint, ne aut ab his, qui coemptas merces supprimunt, aut a locupletioribus, qui fructus suos aequis pretiis vendere nollent, dum minus uberes proventus exspectant, annona oneretur" poena autem in hos varie statuitur: nam plerumque, si negotiantes sunt, negotiatione eis tantum interdicitur, interdum et relegari solent, humiliores ad opus publicum dari.

El jurista nos recuerda en el fragmento la existencia de providencias imperiales dirigidas a reprimir las conductas delictivas de los dardanarios o acaparadores. En base al fragmento y siguiendo a Pollera ${ }^{53}$ son varias las conductas que trataron de reprimirse mediante providencias imperiales, así varias mandatas, como señala el texto, fueron delineando y sistematizando conductas contra la annona, con una fisionomía autónoma, tipificando:

a. cualquier modalidad de acaparamiento con cualquier conducta entorpecedora o anticompetitiva.

b. la sustracción y eliminación de mercancías.

c. la ocultación de productos de mercado para provocar el alza y vender a mayor precio.

d. evitar vender los productos a precios razonables aequis pretiis

Si observamos el texto, aparece la referencia a locupletioribus, qui fructus suos aequis pretiis vendere nollent,.. es decir aquellos que no quieren vender sus productos a precios razonables, como hemos visto en la última conducta, en espera de momentos de carestía para asi aprovechar la demanda y elevar los precios, afectando al libre mercado. Estos latifundistas o locupletiores se equiparan a los dardanarii y no hay razón para establecer una diferenciación dado que lo que se produce es una configuración penal adaptada a la realidad

\footnotetext{
${ }^{53}$ Annonam adtemplare cit. 411 ss.
} 
cambiante, nuevas hipótesis ${ }^{54}$ que van implementar la lex iulia de annona a través de la jurisprudencia y las providencias imperiales. Ulpiano trata de dar una sistematización científica a las conductas en sus libri de officio proconsulis escrito bajo el gobierno de Caracalla, por ello debemos de proceder a un análisis conjunto de otros fragmentos que también mencionan a los dardanarios que veremos a continuación. El final del fragmento trae a colación las penas que van desde la interdicción de negociar a los negotiatores ${ }^{55}$; e incluso, en los supuestos más graves, la relegatio. Y en el caso de los humilliores, la condena a trabajos forzosos; además que se podían aplicar la pena establecida en la lex iulia de veinte aureos.

A este respecto, y continuado con la reconstrucción del delito, debemos analizar tres fragmentos uno es el que viene a continuación del ya citado, también de Ulpiano D.47.11.6.1, otro de Paulo D.48.19.37 y el de Modestino D.48.10.32.

Veamos el primer lugar el de Ulp. (8 de off. Proc.) D.47.11.6.1:

Onerant annonam etiam staterae adulterinae, de quibus Divus Traianus Eidctum proposuit, quo Edicto poenam legis Cornelia in eos statuit perinde ac si lege testamentaria, quod testamentum falsum scripsisset, signasset, recitasset, damnatus esset

Prima facie, se observa la preocupación del emperador Trajano por la provisión de la annona y la lucha por la falsificación de los pesos y medidas, que provoca alteración de precios y distorsión del mercado, aplicándose la pena de la Lex Cornelia de falsis. Está claro que el emperador prefirió subsumir la conducta que trataba de manipular las balanzas o falsear las medidas staterae adulterinae a fin de obtener ganancias dentro del crimen falsi dado que aparecían nuevas figuras como la que se referencia en el texto en relación a los testamentos, y cuya condena era la relegatio, sin distinción de si se trata o no de humiliores como el fragmento pr. Por otro lado, el fragmento D.47.11.6.2 hace referencia a cómo el emperador Adriano también mantiene la pena de relegatio cuando señala: Sed et divus Hadrianus eum, qui falsas mensuras habuit, in insulam relegavit.

Si tratamos de aquilatar y configurar o sistematizar el crimen de annona hemos pasado de la pena de multa a otras de carácter más grave a los negotiatores la interdicción de la negociación e incluso dentro de los honestiores la relegatio o la condena a trabajos forzados, en el caso de los humiliores. La represión y la innovación legislativa en aras a garantizar el buen funcionamiento de los mercados parece hacerse según nos van comentando los diferentes textos a través de mandata principum y otras providencias imperiales. A mi juicio desde Trajano se da una configuración autónoma a una conducta que evidentemente afectaba al mercado por el uso de balanzas o pesas falsificadas o con medición alterada y que el sanciona con la pena de la lex Cornelia, quizá porque las medidas propias de la lex iulia eran insuficientes y se endurece al aplicar a los falsificadores de pesos, sin que se

\footnotetext{
$54 .$. der lex iulia im generellen umschreibender Tatbestand, in dieser Formulierung nicht Bestandteil des ursprünglichen Gesetzesdiktates gewesen sein, sondern wahrscheinlich vom Juristem eintleitend... Der Ausdruck dardanarii muss weitläufig bekkant un verbreitet gewesen sein, den der Jurist sieht sich nicht genötigt, nach Nennung, des Wortes eine Erklärung desselben anzufiggen ... E. Höbenreich, Annona cit. 228 ss.
} 
especifiquen las formas de comisión ${ }^{56}$, la relegatio de la lex Cornelia.

A mayor abundamiento, otro de los textos que debemos de traer a colación para tratar de observar toda la sistemática de las conductas onerant annonam es el de Paulo en el que sólo señala que se castigue a los dardanarios de forma extraordinaria por adulterar las medidas por afectar a la utilitatem popularis, D.48.19.37: In dardanarios propter falsum mensurarum modum ob utilitatem popularis annonae pro modo admissi extra ordinem vindicari placuit.

El texto de Paulo habla de castigar en función de la gravedad de la conducta lesiva pro modo admissi, criterio que se une al de la condición de las personas ${ }^{57}$ ya comentado, si bien el texto destaca la importancia de configurar este tipo de conductas como atentado contra la utilitas publica conectando dos actividades que atentaban contra el orden de los mercados la de los acaparadores, dardanarii con el modum falsum mensurarum. Ello denota, bajo mi punto de vista, una preocupación cada vez más agudizada sobre el abastecimiento del mercado que obliga a mayor control e intervencionismo y por ende a mayor represión penal. Se apela por otro lado a la razones o utilidad pública en lo que concierne a la justificación del delito; si bien ese criterio que constituye un concepto jurídico indeterminado, al que se va acudir en los supuestos de investigación de las hipótesis comentadas, así se referencia en un texto de Marciano sobre los juicios públicos, D.48.2.13 ( Marciano 1 depub.iud.):

Mulierem propter publicam utilitantem ad annonam pertinentem audiri a Praefecto annonae deferentem, Divus Severus et Antoninos rescripserunt. Ffamosi quoque accusantes sine ulla dubitatione admittuntur. milites quoque, qui causas alienas deferre non possunt, qui pro pace excubant, vel magis ad hanc accusationem admittendi sunt. servi quoque deferentes audiuntur.

Donde se establece que por utilidad pública sean oídos por parte del Praefecto annonae aquellos que pueden acusar en relación al problema de las provisiones desde los militares, infamados, esclavos que podían acusar al propietario por defraudación ${ }^{58}$ y las mujeres; texto en el que también se destacan las competencias jurisdiccionales y administrativas del Praefecto.

También Modestino, en relación a la falsificación de medidas y pesos, nos recuerda la pena de la relegatio que también recogía el fragmento de Ulpiano remitiéndose a la misma providencia ex decreto divi del Emperador Adriano D.48.10.32 (Mod.1 de Poen.):

Si venditor mensuras publice probatas vini, frumenti vel cuiuslibet rei, aut emptor corruperit dolove malo fraudem fecerit: quanti ea res est, eius dupli condemnatur: decretoque divi hadriani praeceptum est in insulam eos relegari, qui pondera aut mensuras falsassent.

Este texto conmina a los que hubiesen falsificado pesos y medidas a la pena de relegatio en los mismos

\footnotetext{
${ }^{55}$ FERRINI C., Diritto penale cit. 411 ss.

${ }^{56}$ HÖBENREICH E., Annona cit. 236 ss. en relación a las balanzas y los pesos nos comenta la referencia al Sch1 Bas.60.22.

${ }^{57}$ DE ROBERTIS F., Le variazioni della pena pro qualitata personarum nel diritto penale romano RISG 14 (1939) 59 ss. En igual sentido vid. G. Cardascia, L' apparition dans le droit des clases d'honestiores et d'humiliores, RHD 28 (1950) 47 ss.
} 
términos que el texto D.47.11.6.2(Ulp.8 de offPro.) , antes citado.

Con los textos anteriormente citados, se puede configurar y construir las conductas que afectan a la vexatio y adtemptatio annonae. Así hemos visto como Trajano castigó los nuevos supuestos que iban más allá de la alteración o las conductas que implicaban la coalición para especular, como era el uso de falsificación de pesas o el uso de balanzas adulteradas staterae adulterinae ${ }^{59}$, para las cuales quiso extender la aplicación de la Lex Cornelia de falsariis, tipificando las conductas de los dardanarios bajo el crimen falsi. Adriano omitiendo referencias a la ley Cornelia, impone la relegatio insulam contra las conductas que implicaban la falsificación de pesos y medidas, falsas mesuras. Y la interpretación que a mi juicio parece más verosímil es aquella según la cual parte de una extensión de las conductas del crimen falsi, mediante senadoconsultos, constituciones, y naturalmente a través de la labor jurisprudencial; si bien, se produce una conexión entre las conductas del falsumy las nuevas hipótesis que van más allá de las inicialmente tipificadas por la lex iulia que ahora se amplían a la falsificación de pesos y medidas con el fin de obtener un lucro a consta de afectar a la libre competencia de los mercados. Debe existir, desde nuestro punto de vista, una conexión ${ }^{60}$ entre la referencia a los mandata que contiene el inicio del texto D.47.11.6.pr (Ulp. 8 de off Pro): Annonam adtemptare et vexare vel maxime dardanarii solent: quorum avaritiae obviam itum est tam mandatis quam constitutionibus y la disposición de Trajano, por ello aunque en un primer momento puedo aplicar por analogía a los delitos annonarios estas penas y no sólo para aquellos magistrados encargados de la vigilancia de los pesos y medidas a los que aludía la lex Silia de ponderibus publicis, sino por extensión tratando de endurecer las penas previstas anteriormente por Augusto en la lex Iulia por la relegatio contra esas nuevas conductas que implicaban la falsificación de pesos y medidas que atentaban, siguiendo el razonamiento de. D.48.19.37 (Paulo 1 Sent), anteriormente citado, contra la utilitas popularis; un desarrollo y configuración penal al compas de la aparición de nuevos supuestos que afectaban a la actividad de los mercados, y que demandaban una nueva modalidad de intervención extra ordinem, sometida a la jurisdicción del prefectus annonae.

En otro orden de cosas, existe un fragmento de Ulpiano en el mismo libro VIII de oficio Proconsulis en el que también se hace referencia a la ocultación de mercancías, D.47.20.3.3 (Ulp. 8 de off. Proc): qui merces suppressit, specialiter hoc crimine postulari potest, pero en este caso el delito de referencia es el stellionatus y el texto coincide con la previsión de D.47.11.6.pr (Ulp. 8 de off. Proc): qui coemptas merces supprimunt... En

\footnotetext{
${ }^{58}$ Vid. (Marciano 2 Inst.) D.48.12.1

${ }^{59}$ Existía una regulación que castigaba a los funcionarios que alteraban los pesos y las medidas de forma dolosa, en base a la lex Silia de ponderibus publicis que preveía multas que podían alcanzar la mitad del patrimonio del infractor, si bien no creemos que la disposición de Trajano y su extensión penal solo vaya referido a los magistrados encargados de la vigilancia y conservación de los pesos y medidas. Vid. FERRINI C, Diritto penale cit, p. 400 ss.

${ }^{60}$ En contra RILLINGER R., Humiliores-honestiores.Zu einer socialem Dichotomie im Strafrecht der römischen Kaiserzeit ( München 1988) 245 ss.
} 
primer lugar, en relación al primer fragmento, sabemos que el delito de estelionato ${ }^{61}$ es un crimen extraordinario que da lugar a una cognitio extra ordinem ${ }^{62}$; y en el que además aparece un elemento subjetivo al exigir en su comisión el dolo, pero que se aplica, según señala Volterra ${ }^{63}$, para extender las sanciones del estelionato a nuevas hipótesis como es la ocultación de mercancías.

Ahora bien, la cuestión que se plantea en este punto es, como distinguir las hipótesis a las que va referida el estelionato con la coincidente, ya analizada, del crimen de annona y el de los dardanarii, la punición del primero exige la comisión dolosa y el daño a personas concretas y determinadas, sin embargo en el caso del crimen de annona, es el mercado el que se ve perjudicado y por ende los consumidores, de ahí la mayor legitimación a la hora de formular la acusación ${ }^{64}$.

Es evidente, que el fragmento D.47.20.3.3(Ulp. 8 de off. Proc.) parece referirse, prima facie, al estelionato como una modalidad supletoria al señalar specialiter hoc crimine postulari potest, pero lo cierto es que se trato de agrupar conductas dolosas bajo este crimen cuando la persona o personas a las que afectaba la ocultación de mercancías eran determinadas, si bien la configuración del crimen de annona tenía una variable económica y social importante dado que el bien jurídico protegido es el orden público económico y la lucha contra actuaciones anticompetitivas.

Es cierto que en ocasiones podían producirse mecanismos correctores como los efectos derivados del dumping, en el que se vende a precio inferior del coste, así en concreto nos encontramos con un fragmento que alude a este comportamiento ${ }^{65}$, se trata del fragmento D.48.12.3 pr (Papirio J. 1 de Cogn.): Imperatores antoninus et verus augusti in haec verba rescripserunt: "minime aequum est decuriones civibus suis frumentum vilius quam annona exigit vendere".

En este caso el fragmento va referido a los decuriones ${ }^{66}$, que actúan como agentes de mercado donde la

\footnotetext{
${ }^{61}$ POLLERA A., Annonam ... cit.430 n.85 ve en D.47.20.3.1 (Ulp. 8 de off. Proc.) : Stellionatum autem obici posse his, qui dolo quid fecerunt, sciendum est, scilicet si aliud crimen non sit quod obiciatur: quod enim in privatis iudiciis est de dolo actio, hoc in criminibus stellionatus persecutio. ubicumque igitur titulus criminis deficit, illic stellionatus obiciemus..., el a. habla de naturaleza subrogatoria del delito de estelionato.

${ }^{62}$ D.47.20.2 (Ulp. 8 ad Sab.): Stellionatus iudicium famosum quidem non est, sed coercitoionem extraordinariam spectat..., pero hay que traer a colación también el fragmento, también de Ulpiano, contenido en D.47.11.3 (Ulp. 3 ad Adult.) que señala Stellionatus vel expilatae hereditatis iudicia accusationem quiden habent, sed non sunt publicae, lo cual hace pensar en una acusación privada y no pública vid. VISCONTI, Dardanariatus cit. 12 donde el a. señala: $i$ iudicia relativi non sono pubblici e per quanto la pena sia extraordinaria, pure non é iudicium famosum. Esso non è crimen legitimum, quindi anche la pena non è legitima: e per conseguenza il giudizio relativo si deve fare extra ordinem.

${ }^{63}$ Lo considera interpolado VOLTERRA E., "Stellionatus", Studi Sassaresi 7 (1930) 114 ss.

${ }^{64}$ D.48.2.13 ( Marciano 1 de pub. iud.): mulierem propter publicam utilitantem ad annonam pertinentem audiri a Praefecto annonae deferentem, Divus Severus et Antoninos rescripserunt. Ffamosi quoque accusantes sine ulla dubitatione admittuntur. milites quoque, qui causas alienas deferre non possunt, qui pro pace excubant, vel magis ad hanc accusationem admittendi sunt. servi quoque deferentes audiuntur.

${ }^{65}$ HERZ P, Studien zur römischen cit. 148 ss.

${ }^{66}$ GRELLE. F s.V.« decuriones», in NNDI t.V (Torino 1957) 309 ss
} 
conducta tipificada es la venta a precio más bajo o predatorios que el coste incurrido, para eliminar la competencia, en este caso son los emperadores Antonino y Lucio Vero los que tratan a atajar estas conductas mediante rescripto; afecta por tanto a la dinámica del mercado y a la formación de precios ${ }^{67}$ suis frumentum vilius quam annona exigit venderé Se aprecia, prima facie, unos intereses económicos por parte de los decuriones que actúan como dumpers, quizá movidos por la presión social, si bien, el rescripto de los Divi Fratres trata de impedir la bajada artificial de precios por debajo de los usuales, en esta ocasión la conducta no era realizadas por los especuladores o dardanarios sino por la autoridad pública, los decuriones. También en aras a afectar a una posible volatilidad de precios o a comportamientos anticompetitivos, la providencia imperial impide la fijación de precios libre por parte de ciudades en orden al grano de importanción item scripserunt ius non esse ordini cuiusque civitatis pretium grani quod invenitur statuere.

En igual sentido, se establece un control de precios aludiendo a otro rescripto en el texto de Marciano sobre los iudiciis publicis, D.50.1.8: non debere cogi decuriones, vilus praestare frumentum civibus suis, quam annona exigit, Divi Fratres rescripserunt ... también recogido en el de Paulo Sent, de igual forma, D.50.8.5(6): Decuriones pretio vilori frumentum, quod annona temporalis est, patraie sua praestare non sunt cogendi.

Luego no se prevé en la legislación socioeconómica evitar las prácticas monopolísticas y los precios especulativos no sólo al alta sino también a la inversa un intervencionismo que suponga el abaratamiento artificial de los precios de mercado a los que le afecta los costes de producción, transporte, transacción y oportunidad.

\section{INTERVENCIONISMO Y LUCHA CONTRA LOS MONOPOLIOS}

Frente a estas conductas y a fin de poner fin a la avaricia de la especulación, se llegan a adoptar con posterioridad una serie de medidas como las que adopta el emperador Valentiniano III en una constitución ( Nov.Val 5 pr.-1)

De pantapalolis ad urbem Roman revocandis del año 440, parece permitir el restablecimiento de los monopolios griegos pero siempre con el límite de precios establecido por la Cancilleria:

Graecos itaque negotiatores, quos pantapolas dicunt, in quibus manifestum est maximan inesse multitudinem magnamque in emendis vendendisque mercibus diligentiam, ulterius non patimur sacrae urbis habitatione secludi, licet eos dissensio et máxima invidia tabernariorum quam venerabilis urbis Romae utilitas a negotiatione submoverit. I Idcirco, hoc edicto singuli universique cognoscant pantapolis ad urbem Roman redeundi negotandique licentiam restituam, ut cura pervigili ubertas populo ministretur et in rebus suspectis a maiore multitudine civitas possit habitari, ita ut, si quis statuta pretia non servaverit, in eum pro qualitate facti vindicta procedat nec ob unius aut alterius delitum omne corpus liceat excludi. Ita enim cura multorum nec abundantia deerit et profutura

\footnotetext{
${ }^{67}$ Es importante fijar un nivel minimo de precios para estimular la producción agrícola Vid. CARRIE J "Les distributions alimentaires dans les cites de l'Empire romain tardif', MEFRA 87 (1975) 1096 ss.
} 
civitati augebitur multitudo.

El emperador, nos comenta la avaricia de los negociadores que han especulado en los mercados, si bien utiliza en este caso la pantapolae, a los que después de haberlos exiliado, los hace regresar, dada la presión social, restaurando la negotandique licentiam restituam probablemente garantizando los productos de primera necesidad en especial alimentos y también vestido ${ }^{68}$, sobre todo porque no eran suficientes los comerciantes locales para realizar el abastecimiento de ahí la rehabilitación comercial de los negotiatores griegos, pero con el límite de no abaratar los precios provocando un dumping, sobre la oferta local de ahí la previsión: si quis statuta pretia non servaverit, in eum pro qualitate facti vindicta procedat nec ob unius aut alterius delitum omne corpus liceat excludi.

También existe un control de los monopolios específico, que se une al elenco de disposiciones y concatenación de textos ya analizados, en los que también se persigue las conductas que atentan contra el correcto funcionamiento del orden económico; analizamos ahora dos disposiciones recogidas en el Código de Justiniano bajo la rúbrica De monopoliis et de conventu negotiatorum illicito vel artificium ergolaborumque necnon balneatorum prohibitis et illicitis pactionibus.

La primera de las constituciones es la del Emperador León del año 473, C.4.59.1 :

monopoliis, in quocunque loco vel civitate sint, nullius materiae vel rei utatur, ac ne si sacrum quidem reportaverit rescriptum, exceptis reliquis, neque preces suppeditet vel addere conetur. Ut enim ab omni parte firma maneant bene ita et pie decreta et constituta neque illustrem pro tempore quaestorem, vel reliquos gloriosissimos comités sacrii palatii, vel spectabiles magistros, vel spectabilen secundodecerium aut tertiocerium splendidissimorum tribunorum, vel spectabiles pro tempore referendarios inexpertos imperi, vel alis motus relinquemus, si postea tales quasdam preces susceperint, vel tali cuidam operam suam praebuerint vel supeditando, vel subsignando, vel suggestionibus utendo, vel aliud quoddam momentum vel auxilium offerendo. Qui vero talibus assistunt, sive memoriales sive palatini sive alius militiae sint, quocunque modo tale quid scripserint, vel docuerint vel aliter, ut fiat operam navaverint, amissione cinguli et substataie plectentur. Haec igitur sciens quilibet subditorum quum ex hac nostra legislatione licentiam habeat, utatur hisce de rebus pro lubitu iis conventionibus, quarum nulla est prohibitio.

De la constitución nos interesa el primer párrafo en donde, al margen de estar incompleta, debemos señalar como el emperador de forma general realiza una prohibición genérica sin especificar la materia o producto, si bien, en el último párrafo permite los acuerdos entre comerciantes y operadores mercantiles, de los cuales no exista ninguna prohibición.

Frente a esta prohibición genérica de los monopolios del emperador León nos encontramos con la Constitución del emperador Zenon dada al Prefecto en el año 483 C.4.59.2:

Iubemus, ne quis cuiuscumque vestis aut piscis vel pectinum forte aut echini vel cuiuslibet alterius ad uictum vel ad quemcumque usum pertinentis speciei vel cuiuslibet materiae pro sua auctoritate, vel sacro iam elicito aut in posterum eliciendo rescripto aut pragmatica

\footnotetext{
${ }^{68}$ HÖBENREICH E., Annona cit. 273 n. 250.
} 
sanctione vel sacra nostrae pietatis adnotatione, monopolium audeat exercere, neve quis illicitis habitis conventionibus coniuraret aut pacisceretur, ut species diversorum corporum negotiationis non minoris, quam inter se statuerint, venumdentur. Aedificiorum quoque artifices vel ergolabi aliorumque diversorum operum professores et balneatores penitus arceantur pacta inter se componere, ut ne quis quod alteri commissum sit opus impleat aut iniunctam alteri sollicitudinem alter intercapiat : data licentia unicuique ab altero inchoatum et derelictum opus per alterum sine aliquo timore dispendii implere omnique huiusmodi facinora denuntiandi sine ulla formidine et sine iudiciariis sumptibus. Si quis autem monopolium ausus fuerit exercere, bonis propriis spoliatus perpetuitate damnetur exilii. Ceterarum praeterea professionum primates si in posterum aut super taxandis rerum pretiis aut super quibuslibet illicitis placitis ausi fuerint convenientes huiusmodi sese pactis constringere, quinquaginta librarum auri solutione percelli decernimus : officio tuae sedis quadraginta librarum auri condemnatione multando, si in prohibitis monopoliis et interdictis corporum pactionibus commissas forte, si hoc evenerit, saluberrimae nostrae dispositionis condemnationes venalitate interdum aut dissimulatione vel quolibet vitio minus fuerit exsecutum.

En esta primera parte que transcribimos, se observa como existe una preocupación por parte del emperador sobre conductas colusorias y comportamientos anticompetitivos, que mantiene una constante correlación con las conductas analizadas con anterioridad; así se observa la prohibición de:

Monopolios sobre todo los de productos de primera necesidad, aunque enumera de forma específica vestido, pescado, equinos, añade la expresión victum referida a cualquier producto necesario para el sustento.

Por otro lado, prohíbe la celebración de acuerdos o reuniones ilícitas, illicitis habitis conventionibus coniuraret, dirigidas a controlar el mercado por ejemplo por la creación de trusts que supongan un abuso de posición dominante en el mercado como es negociar para que no se venda por menos de lo que se hubiese pactado, ejerciendo así, un control efectivo sobre los precios.

Prohibiciones para concertar pactos entre constructores y empresarios de subcontratar o desempeñar servicios para que ninguno acabe o ejecute la obra de otro $^{69}$.

En la disposición imperial se establece por un lado una pena que consiste, en el caso del monopolio, en el exilio perpetuo y la confiscación del patrimonio o bienes del condenado. Sin embargo, en la tercera parte del texto se aprecia una persecución específica cuando los empresarios hacen acuerdos o convenciones ilícitos afectando a la libre concurrencia de los mercados y provocando el encarecimiento de los precios. A fin de ponerle coto a dichas conductas, en aras a garantizar la libre competencia, se establecen penas contra los infractores de cincuenta libras de oro y una pena de cuarenta libras al tribunal que no ejecuta las condenas impuestas ante tales conductas colusorias o especulativas.

En definitiva, observando la constitución del emperador Zenón, se trata de nuevo de medidas políticas

\footnotetext{
${ }^{69}$ En otra disposición relativa a los edificios privados del mismo Emperador contenida en C.8.10.12.9 se hace referencia a este aspecto cuando señala:... nec vero alius eiusdem artis ab alio coeptum perficere prohibeatur, quod contra aedificatores ausos fuisse scimus ergolabos artifices, quum neque ipsi ad finem perducerent fabricari a se coepta, neque ab aliis eadem opera consummari concederent, sed intolerabile inde damnum iis inferre operam darent, qui domos exstruere, parant...
} 
marcadas por la constante histórica de la creación de condiciones anticompetitivas de mercado, tendentes a garantizar el desarrollo económico del mercado y por ende el bienestar social por razones de utilitas publica que evite el encarecimiento artificial de los precios.

En el ámbito de los monopolios en el derecho positivo vigente tal y como señalábamos al principio, contamos con la la Ley de defensa de la competencia 15/2007, en la que se prohíbe de forma expresa las conductas colusorias y otros comportamientos que mantienen correlación y coinciden con el Derecho romano.

También nuestro código penal vigente L.O.10/95 de 23 de noviembre, tipifica las conductas punibles que afectan al mercado y los consumidores y que son coincidentes en el supuesto de hecho con la regulación romana en los comportamientos que implican desabastecimiento según el art. 281 que señala:

El que detrajere del mercado materias primas o productos de primera necesidad con la intención de desabastecer un sector del mismo, de forzar una alteración de precios, o de perjudicar gravemente a los consumidores, será castigado con la pena de prisión de uno a cinco años y multa de doce a veinticuatro meses. Incrementándose en situaciones de grave necesidad o catastróficas.

Al mismo tiempo, se contemplan la alteración o manipulación de aparatos de medición conforme al art.283 y el abuso de posición dominante en el mercado que altere la concurrencia competitiva según el art. 284.

Excede de nuestro cometido hacer un análisis exhaustivo de todas las disposiciones normativas del derecho vigente en relación a los monopolios, pero no queremos olvidar en el ámbito supranacional, el artículo 101 (e.81) anteriormente citado del Tratado de funcionamiento de la Unión Europea del que se infiere la huella de algunos de los principios que se deducen de la regulación romana en relación a conductas colusorias que atentan contra la libre competencia, así el texto señala que:

Serán incompatibles con el mercado interior y quedarán prohibidos todos los acuerdos entre empresas, las decisiones de asociaciones de empresas y las prácticas concertadas que puedan afectar al comercio entre los Estados miembros y que tengan por objeto o efecto impedir, restringir o falsear el juego de la competencia dentro del mercado interior $y$, en particular, los que consistan entre otros en: fijar directa o indirectamente los precios de compra o de venta u otras condiciones de transacción; limitar o controlar la producción, el mercado, el desarrollo técnico o las inversiones; repartirse los mercados o las fuentes de abastecimiento.

\section{NOTA CONCLUSIVA}

Como breve reflexión final, venimos a sostener que a lo largo del Derecho romano se repiten las conductas que, por desgracia, perviven hoy en nuestro derecho positivo. En las que la especulación fue una amenaza real, como se pone de manifiesto en los diferentes textos analizados, que parten de una disminución de la producción, sobre todo en el marco de los cereales y otros productos de primera necesidad.(Liv. 36.21.2, Liv. 2.52, Dion Hal.8.70.5), que derivaron en muchas ocasiones en una terrible situación de hambruna, que se intentó encauzar con una serie de políticas intervencionistas frente a las coaliciones de los especuladores que afectaban a la 
libre concurrencia del mercado, mucho antes incluso de la lex iulia de annona, como hemos tenido ocasión de analizar en el fragmento de Plaut. Cap. 3.1.122; dónde ya desde época republicana se perseguía con multa la concitación a fin de especular. Si bien, la configuración de estas prácticas monopolísticas como delito económico, arranca con la lex iulia de annona del año 18 que tipificó los comportamientos, en base al texto analizado de Ulpiano D.48.12.2 pr, que afectaban al abastecimiento, la creación de trust o la confabulación empresarial para atentar contra la libre competencia; incluyéndose, con posterioridad, nuevas conductas como la falsificación de pesos como conductas que atentaban contra la utilitas popularis en base al ya analizado texto de Paulo D.48.19.37. y otras como el dumping, donde los decuriones según D.48.12.3.pr vendían a precios más bajos o predatorios que el coste real del producto, a fin de eliminar la competencia. E incluso, como hemos comentado, la rehabilitación de licencia comercial de los monopolios griegos, desempeñado por los pantapolae por necesidad de abastecimientos, pero siempre bajo el control de los precios marcado por la Administración romana.

Junto a los distintos textos concatenados en los que se configura el control y el intervencionismo de la Administración romana, se observa también a partir del año 473 una constante histórica en la que continua el control de los monopolios por parte de las disposiciones legislativas del Emperador León y Zenón (C.4.59.1 y 2) contra las conductas colusorias e incluso frente a la desidia de la administración cuando el tribunal sancionador no ejecuta la sentencia al cual impone pena de cuarenta libras, por cualquier motivo.

Es evidente, que nos encontramos ante comportamientos que afectan al orden económico establecido y que exigen una intervención contundente en los mercados, incluso, hoy en día a nivel supranacional, hemos visto como muchos de los supuestos de hecho de la regulación romana perviven y guardan una perfecta sintonía en las normas vigentes como la ley 15/2007 en la cual encontramos conductas colusorias que no dejan de ser un trasunto fiel del ordenamiento jurídico romano.

\section{CONDUTA COLORIAL: DA LEI ROMANA A LEI 15/2007 DE DEFESA DA CONCORRENCIA}

\section{Resumo}

No presente estudo, definimos como objetivos o estudo da especulação de mercado no tempo dos romanos tentando abordar os comportamentos que afetam a livre concorrência e que são perseguidos por instrumentos normativos como lex iulia annonaria do ano 18 ao objetivo de manter a ordem nos mercados, uma vez que tentou-se reprimir o acúmulo de alimentos para provocar um aumento artificial de preços, a fim de investigar os princípios que ainda são válidos na lei moderna, como na lei de Defesa dos Alimentos, a lei de concorrência 15/2007 de 3 de julho. Para isso, nossa metodologia é baseada na análise exegética das fontes romanas propostas. Os resultados a serem destacados que também estão refletidos nas notas finais nos permitem observar como há uma transcrição fiel no campo dos comportamentos colusivos do direito romano ao atual. 
Palavras-chave: Conluio; Annona; Monopólio; Dardanarii; Especulação Mercantil.

\section{REFERENCIAS BIBLIOGRÁFICAS}

BAUMAN, Richard, Criminal prosecutions by the aediles, Latomus 33, 1974, p. 257 ss.

BALDSON, J. P. Roman history 58-56 BC. Three Ciceronian problems, Journal Roman Studies, 45, 1957, p. 13 ss.

CARRIE J. Les distributions alimentaires dans les cites de l’Empire romain tardif, MEFRA 87 ,1975),1096 ss.

DE MARTINO, Francesco. Produzione di cereal in Roma nell' età antica, 1979. Storia economica di Roma antica II, Firenze, 1979.

DE ROBERTIS, Francesco. Le variazioni della pena pro qualitata personarum nel diritto penale romano, Rivista italiana per le scienze giuridiche $14,1939,59$ ss.

FERRINI, Contardo, Diritto penale romano, Roma, 1976.

FRAENKEL, Eduard. Elementi plautini in Plauto, Firenze 1960.

GARNSEY, Peter. Famine and food supply in the graeco-roman world, Cambridge, 1988.

GAROFALO, Luigi. Aediles e iudicia populi, Idee vecchie e nuove sul diritto criminale romano, Padova, 1988.

HERZ, Peter. Studien zur römischen Wirtschafsgesetzgebung. Die Lebesnmittelversorgung (Stuttgart, 1988, 148 ss.

HÖBENREICH, Evelyn. Annona, Juristiche aspekte der Stadrömischen Lebesmittelversordung im Prinzipat Graz, 1997.

KOLENDO, Jerzy. L'agricoltura nell'italia romana, Tecniche agrarie e progesso economico dalla tarda repubblica al principato, Roma, 1980 .

LO CASCIO, Elio. Crescita e decline, Studi di storia dell' 'economia romana, Roma, 2009.

MAIER E.G. Römische Bevolkerungsgeschichte Uninschriftenstatt, Historia 2, 1953, p. 318 ss.

OLIVA, Alberto. La politica granaría di Roma antica dal 265 a.C. al 410 d.C. Saggio di agricultura ed economia rurale, Piacenza, 1930

POLLERA, Antonio. Annonam adtemplare et vexare vel maxime dardanarii solent, D.47.11.6: note sulla repressione dei crimini annonari", Index 19, 1991, p. 406 ss.

RESINA SOLA, Pedro. Prácticas monopolísticas e intervencionismo público en materia de mercados, en S. Bello y J.Zamora, El derecho comercial, de Roma al Derecho moderno, Las Palmas de Gran Canaria, 2007. 
RICKMAN, Geoffrey. The corn supply of Ancient rome, Oxford, 1980.

RILLINGER, Rolf., Humiliores-honestiores. Zu einer socialem Dichotomie im Strafrecht der römischen Kaiserzeit, München 1988.

ROSTOVZEV, Michail. Storia economica e sociale dell'impero romano, Firenze, 1933.

ROTONDI, Giovanni. Leges publicae populi romani, Milano, 1912.

TORRENT, Armando. Crimen annonae y mantenimiento del orden público económico, en El derecho comercial, de Roma al Derecho moderno Las Palmas de Gran Canaria, 2007, p. 1008 ss.

VEYNE, Paul. Le pain et le cirque sociologie historique d'un pluralisme politique, Paris, 1976.

VIRLOUVET, Catherine. Famines et émeutes à Rome des origines de la republique a la mort de Neron, Roma, 1985.

VISCONTI, A. Dardanariatus e monopolium come reati control'economia pubblica, Ann.

VOLTERRA, Eduardo., "Stellionatus”, Studi Sassaresi 7, 1930, 114 ss.

Trabalho enviado em 01 de março de 2018.

Aceito em 02 de abril de 2018. 